\title{
ICTs Applied to Formal Foreign Language Aural- oral Assessment: ORALEX* and Communicative Language Competences in English
}

\author{
María I. Casado Antoniazzi \\ Centro Universitario Villanueva Teachers' College, Universidad Complutense of Madrid, Madrid, Spain \\ Email: icasado@villanueva.edu
}

\begin{abstract}
This article analyses a computer-assisted system of formal aural-oral assessment of English, appropriate both for the contents taught in the classroom and the communicative language competences acquired when learning a foreign language. ORALEX was designed ad hoc for easing the teacher's/evaluator's role. It responds to the need for evaluating learners' skills in English, following the Common European Framework in a more efficient and effective way: efficient, because ORALEX can boast of disruptive innovation (easy means, excellent results); effective, because ORALEX facilitates group test-taking as opposed to individual face-to-face encounters. Thus, there is a twofold purpose to this article. Firstly, to show how a communicative approach to learning a foreign language is indirectly facilitated by ORALEX. And secondly, to highlight how communicative language competences might be assessed using this same tool effectively, while emphasising the students' learning autonomy and their performance as active agents of their own linguistic experiences. The article will include a discussion about aural-oral exercises currently being used in ORALEX within the framework of linguistic, sociolinguistic and pragmatic competences. ORALEX can be used in multiple scenarios: EFL, ESL, bilingual or any other situation where aural-oral skills require testing. Furthermore, its flexibility makes it appropriate for schools, academies, training centres, universities, etc. regardless of the level of the foreign language tested or the number of students or subjects to be examined simultaneously, as long as there is one computer available per student.
\end{abstract}

Index Terms - ICT, oral assessment, competences, software, computer, autonomous learning, EFL/ESL

\section{INTRODUCTION}

The Foreign Language Department at Centro Universitario Villanueva Teachers' College, an accredited Higher Education Institution affiliated with the Universidad Complutense de Madrid, has been training student teachers since its foundation in 1978. These student teachers are granted a degree in teaching education to teach English at the kindergarten, infant and primary school levels. Exams have always been part of this University's programme. However, only written exams were administered initially. As time went by, the need for oral testing became apparent. Oral assessment started in $1998^{1}$ and can be considered as achievement and progress testing on account of its aim (Madrid \& McLaren, 2004: 450).

Since then, our Foreign Language Department has made oral exams compulsory to formally test students' oral proficiency in a foreign language -in our case, English- because our institution places increasing emphasis on aural-oral communication. Teachers of English at Centro Villanueva have formally been assessing their student teachers' written and oral command of the language in subjects such as English Language I, II and III, Phonetics, etc. There are certain weighty reasons why formal aural-oral assessment is fostered. Firstly, our student teachers have to be ready to perform in any English-speaking environment. Secondly, they have to teach English, mainly orally; therefore, their oral skills must be up to par. Thirdly, oral exams put students through tense situations; this experience trains student teachers to perform under pressure, which will help them perform in their future job interviews or in classroom activities where parents (native speakers, perhaps), school and Ministry authorities, etc. might be present. Fourthly, oral exams test student teachers' fluency as well as accuracy in a foreign language. English phonetics, grammar, etc. are thus put into practice and oral exams become a true assessment of the theory learnt in other subjects. Fifthly, students consider them very important. $^{2}$

As might be inferred, the formal aural-oral assessment process has undergone a series of adaptations to suit the students' and teachers' needs. In the early stages, students who attended either regular or monthly classes were assessed

\footnotetext{
* ORALEX is an in-house developed software package, designed by the Department of Foreign Languages at Centro Universitario Villanueva. The technical advice and support was mainly provided by Juan Luis García Martín, the ICT Department head of Centro Universitario Villanueva.

${ }^{1}$ Distance education assessment (López, Alba-Juez, Aragonés \& Molina, 2006; AudioAssessment.com, 2008) is totally unrelated to our model.

${ }^{2}$ In a survey done in May-June 2010, 73 questionnaires were passed. $92 \%$ of the respondents thought oral exams were very important to test foreign language proficiency.
} 
in teacher-student face-to-face encounters. However, since time spent on formal aural-oral assessment became totally unrealistic, there was an urgent need for an improved testing procedure, time-saving in this whole process being tantamount to success (Larson, 2000: 54). We thus went from individual face-to-face assessment to group test-taking through the local area network, for post assessment, through ORALEX.

ORALEX is an easy-to-use software programme used in testing aural-oral foreign language skills. When designing ORALEX, it was imperative to maintain all the benefits of the face-to-face encounters while adding others. The communicative approach to teaching/learning followed in class could not get lost in translation. Thus, a brief practical description of how this approach is used in class will be outlined as a springboard for the formal aural-oral assessment.

\section{THEORETICAL BACKGROUND}

The communicative approach views language as an interactive tool: to express oneself, to express one's views to others, to listen to the views of others, and to interact. Under this approach, language is used for communication (Bachman, 1990; Brumfit, 2001; Harmer, 2001; Johnson, 1982; Larsen-Freeman, 1986; Littlewood, 1981; Munby, 1978; Richards \& Rogers, 1986; Widdowson, 1978; Wilkins, 1972). To achieve communication, the communicative approach makes use of authentic language, speech acts and different speech registers, dialects and language varieties.

Authenticity can surface at two levels, situational and interactional, and both can be present in assessment. Testing shows situational authenticity when the task is an accurate representation of some language activity which takes place in everyday life. Interactional authenticity appears when we try to use situations and tasks which are likely to be familiar and relevant to the students (Bachman, 1990; Widdowson, 1978). Speech acts are categories of communicative functions (Wilkins, 1976, in Madrid \& McLaren, 2004: 318). Any expression which conveys the speaker's intention can be considered a speech act, that is, with its corresponding illocutionary value (Austin, 1962, in Madrid \& Hughes, in Madrid \& McLaren, 2004: 53).

Furthermore, genuinely communicative activities exhibit three features: information gap, choice and feedback. An information gap occurs when one person in the conversation misses some piece of information. Then, the participants can choose what to say and how to say something: "To fill the information gap, participants in the conversation need feedback to know whether their communication is being successful” (Johnson \& Morrow, 1981, in Megías \& Santamaría, in Madrid \& McLaren, 2004: 320). In such activities, exercises cannot be tightly controlled.

Recapitulating, I have chosen to call the three natural features of communicative activities an interactive loop, which can be assessed by ORALEX with some limitations.

\section{COMMUNiCATIVE APPROACH TO TEACHING/LEARNING (CLT)}

A communicative approach to teaching/learning at our University has been eased by the contents taught as well as the methodology used in class, upon which the Internet has had a great bearing. Our student teachers need to engage in meaningful and authentic language use to master communication at all levels, including school children's linguistic level. They should become familiar with everyday English as well as classroom English, in order to interact with society and with their prospective students. ${ }^{3}$

Since a class scenario is not $100 \%$ real, the actual communicative experiences need readjusting in the classroom. To achieve such a goal, "problem solving activities can, for example, focus on language study: proverbs, idioms, traditions, games, rhymes and songs, etc. and through apparently quite controlled elements on the part of the teacher, they may still retain the three principles (of interaction) mentioned above" (Megías \& Santamaría, in Madrid \& McLaren, 2004: 323).

English Language I will be analysed, to see how these objectives at our University are fulfilled. The contents of this subject encompass broad-ranging areas, covering a number of everyday home life and school situations that student teachers can find themselves in when travelling abroad, doing their teacher training, and/or after graduating. The following description exemplifies how the class activities in this subject have been adapted to the communicative approach.

The corresponding units cover Food, ${ }^{4}$ The Family, ${ }^{5}$ People and Clothes, ${ }^{6}$ The Weather ${ }^{7}$ and Travelling. $^{8}$ Home reading materials provide further reinforcement of the units. By way of example, the first unit - Food- will be tackled.

\footnotetext{
3 "In the late 1980s Bachman (1990) presented his first comprehensive view of communicative language ability (CLA), which clearly grew out of the work of Canale and Swain. He suggested that CLA consists of language knowledge or competence combined with the ability to execute that competence in appropriate language use" (EALTA Guidelines, 2006: 3).

${ }^{4}$ Materials drawn from e.g. http://www.nourishinteractive.com/kids/kidsarea.html; http://www.kidsacookin.ksu.edu/ (accessed 9/9/2010); Charlie and the Chocolate Factory DVD.

${ }^{5}$ E.g. Website The Ugly Duckling, http://www.youtube.com/watch?v=WMKxnYRhk6I (accessed 9/9/2010); Charlie and the Chocolate Factory DVD, etc.

${ }^{6}$ E.g. http://www.esl-lab.com/ (accessed 9/9/2010), etc.

${ }^{7}$ E.g. http://www.fema.gov/kids/twins/ (accessed 9/9/2010), etc.

${ }^{8}$ E.g. Song I'm going home by Chris de Burgh; http://video.yahoo.com/watch/1548669/5256177 (accessed 8/6/2009).
} 
In it, students become familiar with eating healthily, the food pyramid, how to trick children into eating veggies, gardening projects, food games, teaching youngsters how to cook and especially appealing recipes for children. ${ }^{9}$

As regards the methodology used in class, classes are regularly held through social interaction, dialogues, role-plays, debates, presentations, round-table talks, etc. where our students learn to express themselves. They exchange "information and opinions [with their classmates], talking about their likes and dislikes and recounting their experiences The emphasis is firmly on language as a social instrument, or a way of enabling people to interact with one another" (EALTA Guidelines, 2006: 3). The website materials included in each unit ensure this interaction. ${ }^{10}$

Two conclusions can be drawn from all the above: in the first place, the contents are real, adapted to the student teachers' needs. They should feel there is a synergy between the knowledge acquired and its applicability. Secondly, if the contents taught in the classroom, if the materials chosen and if the activities done do not follow the communicative language teaching approach, aural-oral assessment can do very little to promote communication. When oral assessment tries to test communication skills which have not been practised before, the result will most likely be below expectations. ${ }^{11}$

Therefore, for oral exams to accomplish their aim, the activities should be coherently designed, following the teaching/learning approach developed in class. Reading, model imitating, paraphrasing, answering or asking questions, narrating, arguing for and against, summarising, etc. are regularly part of the aural/oral assessment exercises.

The techniques of language testing in use at any time tend to reflect the view of language and the way it is used at that time. What is being tested and the kind of task or item type chosen as a means of testing can be expected to show the influence of current thinking on what language ability is and what exactly we are doing when we use language in everyday life. (EALTA Guidelines, 2006: 1).

\section{OBJECTIVES}

There have been several challenges along the way in our aural/oral assessment throughout the history of ORALEX. Thus, a first step is to show how a communicative approach to teaching/learning a foreign language is facilitated by ORALEX. Coherence between the teaching/learning approach used in class and the way assessment is carried out is mandatory. Coherence itself, however, is not enough when assessing. The procedures call for efficiency. This explains why ORALEX makes it possible to minimise human and material resources while maximising benefits. The second step, linked to the first, is to highlight how communicative language competences can be assessed effectively through ORALEX. This software replicates the classroom approach to a large extent. Both objectives take for granted that a fundamental tenet behind any kind of formal aural-oral assessment is to ease the evaluator's role in testing language abilities. This is the reason why the initial one-to-one face-to-face encounters developed into group test-taking through LAN (Local Area Network).

\section{METHODOLOGY}

\section{A. ORALEX and the Communicative Approach to Learning. The Assessment Experience}

Generally speaking, all encounters with a foreign language are a learning experience for students and teachers alike. Formal aural/oral assessment with ORALEX is an enlightening experience for both parties: teachers get to know if their efforts have been productive and students discover whether their studies have proved satisfactory. These premises are especially true in a communicative approach, where students have to apply their newly acquired knowledge to real-life situations. In fact, students have often commented that Villanueva University staff teaches them how to perform orally, without neglecting the other skills. ORALEX constitutes, no doubt, a major contribution to oral assessment as a userfriendly tool.

Some examples of communicative exercises included in the formal oral exams using ORALEX are the following:

- Dialogues. Students have previously role-played dialogues in class, using real English. They may be asked to act out one of the dialogues. Another exercise might be to role-play one of the dialogues, interpreting the two characters. Another exercise supplies some expressions used in the dialogues and students have to use them in context. These can be understood as controlled activities, but there is another one that gives complete freedom to the students: they can invent a dialogue by combining some of the dialogues studied before. Although there is an information gap and a choice in these exercises, these are individually performed, that is, each student is in front of a computer. Interaction is simulated.

\footnotetext{
${ }^{9}$ As an aside, it can be helpful to comment that dancing and singing relieves tension and arouses the students' enthusiasm while setting an example to imitate later on. There is a dance song in the film Charlie and the Chocolate Factory, performed by the Umpa Loompas dancing at work, that was sung while dancing in the English class.

${ }^{10}$ All the units are uploaded onto the University website.

${ }^{11}$ Obviously, no methodology can fully compensate for students who do not take their studies seriously.
} 
- Paraphrasing. Here there is also an information gap and a choice. Students can use multiple expressions from the different texts and explain or give synonyms for the phrases provided. They have access through the web to all the possible expressions to paraphrase, so that they are not taken by surprise.

- Song recitation. The Ugly Duckling, the Umpa Loompas' dance song from Charlie and the Chocolate Factory and others provide materials for students to sing and recite the songs. There may be questions on the songs themselves to check their knowledge of lexical items, grammar (e.g. if the questions on the song are in the Simple Past, with the use of irregular verbs), idiomatic expressions, etc.

- Retelling of stories, where students narrate one episode of their choice.

- Reading of excerpts from previously studied texts, where students have to perform as best they can, taking into account pronunciation, intonation, stress, rhythm, etc.

- Open-ended stories, for the students to finish.

- Questions and answers on any of the texts studied in class.

- Agreeing or disagreeing with a comment, justifying their views.

- Summary of a text.

- Listening/repetition following a model.

- Comments on videos studied in class, discussing main ideas, what impressed them most, their views, comparing them to their own experiences.

All the texts are accompanied by either audio or audio-visual materials.

\section{B. Competences Assessed by ORALEX through a Selection of Oral Exercises}

"A model of language ability is of importance to the language tester because it provides a useful basis for defining the area of competence to be tested" (EALTA Guidelines, 2006: 4).

There are certain oral exercises that the teachers of English at Centro Universitario Villanueva have considered compulsory to do in class to train student teachers properly. The sample exercises detailed later on have been practised regularly in the normal classroom as well as in the computer room before taking the formal oral exams. There is a whole range of them. This variety obeys the need to cover all aspects of communicative language competences, which can be classified as linguistic, sociolinguistic and pragmatic (Common European Framework, 2001; Madrid \& McLaren, 2004: 454). ORALEX offers the possibility of testing all of these competences.

Linguistic competence comprises lexical, grammatical, semantic, phonological, orthographic and orthoepic subcompetences (Madrid \& McLaren, 2004: 454). This competence calls for fluency as well as accuracy in content and form. It can be tested through several exercises, such as paraphrasing. Besides lexical knowledge, paraphrasing puts several other aspects to the test: grammatical -the explanations have to be accurate-; semantic -the right meaning must be known in order to paraphrase correctly-; phonological -since the words to be paraphrased are spoken orally and the pronunciation, intonation, etc. should be accurate not to impede communication-; orthographic and orthoepic -students have to be aware of the relationship between the pronunciation of words and their orthography-.

Sample materials used for paraphrasing are in the unit on Food: Dinner time, ${ }^{12}$ where there are vocabulary items with their explanations at the end of the dialogue; and in the one on The Family: The Ugly Duckling, ${ }^{13}$ where the unknown lexical items have been worked on in class.

Linguistic competence can easily be assessed through the narration of an event, part of a story, etc.

Give a very short presentation based on the video of the recipe you chose. Give the name of your recipe when you start (15 points) (see Appendix C).

Another oral exercise to test linguistic competence is to read an excerpt.

FIRST PART: Start reading when you are ready (15 points) (page 20, The Fruitcake Special) (see Appendix D).

Another exercise consists in listening to an excerpt and giving the main ideas or answering questions on it. An additional activity to test linguistic competence is the listening/repetition type. There are fixed pauses between speech acts or sentences. Students record their voices in the spaces provided, following the model: pace, intonation, stress, pitch, pronunciation, etc. The closer they imitate the model, the higher the mark. Fluency and accuracy are promptly evidenced. Their recording also throws light on comprehension. If comprehension is lacking, this kind of exercise is a total failure. Moreover, the idea behind it is to test whether the students have developed certain memory/brain training as a result of their own individual work at home.

Listening/repetition exercise (20 points). You will hear 5 clauses with spaces in between. Remember the pauses are provided for you, so please do not touch the mouse until the end. Thanks - that will be all. Press next to start (page 62, The Book of Thoughts) (see Appendix D).

Reciting memorised texts, previously analysed in class, develops linguistic competence and proves very practical to assess orally. This type of exercise improves their reading as well as their role play activities. Our experience shows that

\footnotetext{
${ }^{12}$ Audio/written http://www.esl-lab.com/cook/cookrd1.htm\#vocab (accessed 7/7/2008).

${ }^{13}$ Audio/written http://www.jellybabys.co.uk/bedtime_stories/ Ugly_Duckling. mp3 (accessed 7/7/2008).
} 
there is a major improvement when comparing the first and last month of University freshman year ${ }^{14}$. The students' self-confidence in language production is reinforced by memorisation. Students whose level of English is quite low are able to reproduce paragraphs imitating the model, which boosts their self-esteem. Memorisation is passive production, and passive activities increase their self-confidence. Excerpts from Getting a Haircut, Hanging Out with Friends, Nice to Meet You, i.e. dialogues on people and ordinary situations, encourage the students to perform in public. Fluency and accuracy are not the target here. Brain training is: for example, how well students can remember episodes under pressure. This aspect can be considered fundamental in a foreign language to help develop all the competences at length.

Retell Hello shoppers, here is a lost boy named Marshall (15 points) (see Appendix D).

So far ORALEX has made it possible to assess linguistic competence individually. Now, the challenge is to wrestle with real language use, in social activities, to assess sociolinguistic competence. Sociolinguistic competence involves markers of social relations, politeness conventions, expressions of folk wisdom, register differences, dialect and accent (Madrid \& McLaren, 2004: 454). Lack of knowledge of this competence might upset communication; for instance, when a foreigner uses an inappropriate word that goes against the rules of communication. An adequate selection of authentic language materials is of utmost importance to succeed.

Most of the dialogues from unit 3 -People and Clothes, Lost in the Crowd, ${ }^{15}$ Nice to Meet You, ${ }^{16}$ Just a Haircut, Please ${ }^{17}$ Expressing Condolences, ${ }^{18}$ etc.- offer use and choice of greetings, address forms, register of discourse (formal, informal), etc., familiar quotations and everyday life expressions. Dialect and accent are exemplified, for instance, in one of the YouTube videos describing Immigrants from Mali (Unit 5, Travelling). The narrator is an African immigrant speaking English, with a marked French accent. ${ }^{19}$ Moreover, the home reading materials are read by British and American people so that students get exposure to both accents.

Pragmatic competence can be divided into discourse and functional.

[They] are concerned with the user/learner's knowledge of the principles according to which messages are:

a) organised, structure and arranged ('discourse competence')

b) used to perform communicative functions ('functional competence')

c) sequenced according to interactional and transactional schemata ('design competence)". (Council of Europe, 2001: 123).

The discourse competence is the ability of a user/learner to arrange sentences in sequence so as to produce coherent stretches of language. It includes knowledge of and ability to control the ordering of sentences in terms of given/new information, coherence and cohesion. The functional competence is concerned with the use of spoken discourse and written texts in communication for particular functional purposes. It includes knowledge of speech acts and categories such as description, narration, instructions, and conversational patterns such as questions-answers, etc. (Madrid \& McLaren, 2004: 322-323).

The exercises to be assessed are the same as under sociolinguistic competence. However, the focus on them varies. Here attention is drawn to the coherence of the dialogue, to the clarity and sequencing of ideas. Therefore, the forms of language are longer than sentences, such as stories, conversations, business letters, etc. (Missouri State University). ${ }^{20}$

SECOND PART: One question on Finders Keepers (15 points): What is the name of the game and what is the relationship between the title and the story? (see Appendix D).

The home reading materials give ample room for the assessment of discourse competence. This competence focuses on how students develop the capacity to get their messages across, to express their views and incorporate those of their interlocutors.

One question on Brains (15 points): What was the effect of Gina Capaldi's drug on Max?" (see Appendix D).

In the question-answer activities, they may have to justify, for example, why a certain character in one of the stories has behaved the way he has, ${ }^{21}$ or describe a character's development throughout the story, ${ }^{22}$ or explain how they would react if they were in that situation. ${ }^{23}$

The question-answer exchange also allows students to manipulate the situation. For instance, they have to convince their interlocutor whether the drug used on Max, a monkey, to raise his intelligence, was moral or not, ${ }^{24}$ defending their views, agreeing or disagreeing with their interlocutor's point of view.

\footnotetext{
${ }^{14}$ From now on, it will be possible with ORALEX to carry out studies systematically to statistically confirm what has been experienced all these years and what students themselves have manifested, especially after finishing their studies with us.

${ }_{15}$ Audio/written free online http://www.esl-lab.com/lost/lostrd1.htm (accessed 7/7/2008).

${ }^{16} \mathrm{http}: / /$ www.esl-lab.com/childintro/childintrord1.htm (accessed 7/7/2008).

${ }^{17} \mathrm{http}: / /$ www.esl-lab.com/cut/cutrd1.htm (accessed 7/7/2008).

${ }^{18} \mathrm{http}: / / \mathrm{www}$. esl-lab.com/insurance/insurancerd1.htm (accessed 7/7/2008).

${ }^{19} \mathrm{http}: / /$ www.youtube.com/watch?v=VMC3jbQN5gI (accessed 7/7/2008).

${ }^{20} \mathrm{http}: / /$ vlc.missouristate.edu/languagelearning/competence.asp (accessed 7/9/2010).

${ }^{21}$ In The Fruitcake Special, Mr. Amos's behaviour. Likewise, in Brains, the reason for Mr. Dimitry's attitude towards his PhD student.

${ }^{22}$ In The Book of Thoughts, if the main character changed or not and why he did or not.

${ }^{23}$ In The Real Aunt Molly, the decision her family had to make.

${ }^{24}$ Brains, in The Fruitcake Special.
} 
Discourse competence can further be assessed through problem-solving. In Finders Keepers, a whistle got broken, but before it did, it had the power to stop time. One question to the students was: "what would you do if you had that whistle?".

Regarding functional competence, the focus is on when to say what, i.e. the ability/knowledge shown in interaction. Answering questions enables the teacher to check students' comprehension as well as production.

Please answer the following questions on the dialogue between father and daughter Dinner Time in a complete way (15 points). PRESS NEXT TO CONTINUE
1. What does the father say about his experience cooking?
2. What does the girl say about pumpkin?
3. What happened at the end? (see Appendix C).
All these questions had been previously debated in class.

\section{STUdents AS AGENTS OF THEIR OWN LEARNING}

ORALEX relies heavily on autonomous assessment. Students act as agents of their own assessment procedure. To illustrate this theory further, there are two sets of instructions in ORALEX: the first screens that appear contain rubrics for testing sound, recording, etc. The second set of instructions is verbal and corresponds to the exam per se. At the beginning, students follow the instructions on the screen and act accordingly. These instructions are simple enough for the students to complete the end of the exam without further help. This peculiarity has been recently improved by preparing ORALEX instruction screens in one colour, and the exam itself in another colour. The instructions can be in any language; English was our choice. When the exam starts, students are in control of time: when to start recording, when to stop, where to stop. They take their exams at their own pace. Time control on the part of the students in all the exercises but one relieves them of much anxiety.

ORALEX can boast of transparency in the procedure. After finishing the exams and before handing the exam audio file in, students have the opportunity to listen to their answers, in spite of the fact that no changes are permitted. Through that mechanism, students can know how they have done. Thus, any unrealistic idea of their performance is easily discarded. Occasionally, students have been asked to write on a sheet of paper the mistakes they thought they had committed. Although this is not consistently carried out due to lack of time, students consider it a very positive experience. This exercise reveals language awareness and should not be discarded. ${ }^{25}$

Students are agents of their own learning in another important aspect. The rubrics of ORALEX instruct them very clearly on the marking scheme. They know how they are going to be assessed, i.e. which activities are worth more points. ${ }^{26}$ Moreover, the numbers of parts and types of exercise are specified at the start of the exam for the students to know what to expect, namely, if the oral exam includes some reading, a listening/repetition exercise, a question and answer part, paraphrasing, etc.

Another aspect that emphasises students as agents of their own learning is the individual assessment of their oral exams. Although they are taken in groups, their recorded answers are assessed by their own teachers one by one. This close bond encourages a personal relationship, personalised assessment with recognition of effort, dialogue and provides feedback (Sangrà, 2010).

Students can listen to their exams and are encouraged to do so at revision times. Furthermore, they know that the recorded files are at their disposal. If strong disagreements between student and teacher arise, there is always the possibility of summoning a board to arbitrate on the final mark. Since exams are recorded, saved and filed through the LAN, on readily accessible simple files, this is feasible at any time.

Students are in control of whatever information there is on their performance because of the tangible proof that the saved sound file provides. Moreover, each student's assessment record becomes part of the university database, a key element in the whole process of the evaluation of competences (Escamilla, 2010). These are key assets of ORALEX.

Quantitative and Qualitative Evaluation with the Help of ORALEX

The last point to touch upon is quantitative and qualitative assessment. "Are marking schemes/rating criteria described?" is one of the questions posed in EALTA Guidelines (2006: 3).

Generally, marking schemes involve the use of a rating scale, which may break down the skills being assessed in a speaking test into areas such as pronunciation, fluency and accuracy (grammatical, semantic, etc.), and mark each on a scale. The final score for such tasks is reached by giving a mark on each scale, so that a total score for the task is an aggregate of the past scores (EALTA Guidelines, 2006: 243).

Quantitative as well as qualitative assessment follows quantifiable standards. They both tackle contents and form. As regards form, linguistic competence needs assessing in terms of grammar, phonetics, etc. A scoring system is used, which students know ahead of time. Concerning contents, wrong contents can be the sign of poor linguistic competence (e.g. semantic), or poor pragmatic competence (lack of ability to justify opinions, express ideas). Qualitative assessment

\footnotetext{
${ }^{25}$ Pena Díaz \& Porto Requejo consider this aspect should be taken into account before final assessment, i.e. what they call "evaluación formativa" (2010: 351).

${ }^{26}$ The syllabus designed and uploaded on the web clarifies the possible mistakes and the points marked off for each (if they are grammar mistakes: simple present, simple past, word order, etc.).
} 
requires clear items to rate: straightforward messages, lexical variety, coherence, etc. Students are also informed of how these aspects are assessed. A certain percentage of the final mark corresponds to global achievement. Rarely do borderline doubts arise in assessment. Should this happen, the decision can be taken at departmental level. Thanks to ORALEX, recording students' performance is tantamount to success.

\section{ORALEX AND DISRUPTIVE INNOVATION}

One last word on ORALEX and disruptive innovation: our software was the outcome of an urgent assessment need. It originated in the academic world, not in the business sector. This might account for the minimising of human and material resources while maximising benefits. The results positively outweigh the investment: it functions with inexpensive means. ORALEX does not follow the pattern of incremental innovation. This justifies why it can suit the objectives of any educational centre, even those which cannot invest in more expensive technology.

\section{CONCLUSIONS}

Currently ORALEX is not multimedia; it only allows for the oral exams to be carried out by means of audio listening and recording (López, Alba-Juez, Aragonés \& Molina, 2006: 3). Nevertheless, foreign language testing greatly benefits from this software programme. This software can be used whenever aural/oral skills testing is necessary. In fact, those disciplines which help develop presentation skills, negotiation skills, etc. can also benefit from ORALEX.

All foreign language competences -linguistic, sociolinguistic, and pragmatic- can be readily assessed with the help of ORALEX. However, pragmatic competence is assessed through controlled exercises. There is no fully free interaction yet.

In other respects, students perform as agents of their own assessment procedures. Rubrics and verbal instructions allow them to complete the exams unattended. They are also in control of time. Since ORALEX provides tangible proof of the students' performance, the assessment process is transparent. The exams can even be corrected by another party.

Due to the varied environments, ORALEX can be used at all kinds of educational levels, even competitive exams or any other type of exam -Cambridge, for example- and educational sites as well: centres, schools, institutes, private or public institutions, etc. Moreover, ORALEX requires minimum investment.

Exams resulting from formal aural/oral assessment are filed, stored, and easily accessed (see Appendix E), ready to be used for other purposes if needed besides assessment. By the end of this school year, there will be sufficient data collected to carry out research on the assessment of competences based on the last three years.

"What attention is given to the appropriate analysis of assessment results? What use is made of the results?" (EALTA Guidelines, 2006: 2). The goals have been amply fulfilled.

\section{ONGOING RESEARCH}

ORALEX 2.0 will be multimedia. Aural/oral assessment of picture comparison will be possible. Comparing pictures increases the ideational feature of discourse competence: "Compare these houses and decide which one you would like to live in". The incorporation of video clips will provide more pedagogical tools to assess functional competence: "Express your views on the old man's behaviour in UP" or "Discuss the benefits of eating healthily and education in August Gloop's family in Charlie and the Chocolate Factory". The assessment of pragmatic competence will be enhanced by real interaction between two or more students, a longed-for goal. The videos will encourage pair discussion. The principle of autonomy, of students regulating their learning, will be improved by having their answers on audio files on their desktops at their disposal. Finally, ORALEX 2.0 will allow assessment online, via the web.

APPENDIX A ORAL EXAM MONDAY, JUNE 21st, 2010

Name:

$1^{\text {st }}$ semester

Group:

1. You are the cook and you are teaching an 8-year old child to cook. What 3 pieces of advice can you give him? (15 points, 5 points each).

2. Narrate the episode you chose from the UGLY DUCKLING (15 points).

3. Describe Grandma Georgina, one of Charlie's grandparents (10 points).

APPENDIX B ORAL EXAM FRIDAY, JUNE 25TH, 2010

Name:

Group:

Oral Unit III. PEOPLE AND CLOTHES dialogues (total 70 points: 10 points each)

Pass: 40 Good: 56 Outstanding: 65 Distinction: 70

There are 7 questions on 3 different dialogues.

Dialogue: A Fun Day

1. What time does the film start this afternoon?

2. Why can't Mom go with them? 
Dialogue: Just a Haircut, Please!

3. Why does the customer go to the beauty parlour?

4. Why doesn't the customer have much time?

Video: My Family Roots: Genealogy

5. Where was Ana Maria Cavazos born?

6. What did they experience?

7. Where did Ana grow up?

Subtotal: 70

\section{APPENDIX C ORAL EXAM FOR ENGLISH LANGUAGE I, TITULADOS MADRID}

Groups A and B

Name:

Units I, II and III (except home reading)

Date: February $19^{\text {th }}, 2010$

This oral exam consists of 5 different exercises. Listen carefully as no repetition of either instructions or questions is allowed. Total number of points, 70. Pass: 40 Very good: 55 Outstanding: 63 Honours: 70. PRESS NEXT TO CONTINUE

I. Read an excerpt provided by the teacher (any of the 11 dialogues from this unit) (15 points)

II. Please answer the following questions on the dialogue between father and daughter Dinner Time in a complete way. (15 points) PRESS NEXT TO CONTINUE

1. What does the father say about his experience cooking?

2. What does the girl say about pumpkin?

3. What happened at the end?

III. Give a very short presentation based on the video of the recipe you chose. Give the name of your recipe when you start. (15 points)

IV. In the first part of the film Charlie and the Chocolate Factory describe how Veruca and Charlie reacted when they found the golden ticket. (15 points)

V. Retell "Hello shoppers, here is a lost boy named Marshall". (15 points)

\section{ApPEndix D Home ReAding EXAM, MAy 21st, Titulados Madrid, Group A, 4:15 PM}

Name:

Make sure you are in your computer session. Please pay special attention to content as well as form. There are 3 parts to this exam. FIRST PART: reading of a paragraph provided by the teacher. SECOND PART: two questions on the stories. THIRD PART: Listening/repetition (total 65 points). Pass: 35 - 55....Very Good: 56- 60....Outstanding: 6164....Distinction: 65....PRESS NEXT TO CONTINUE

1. FIRST PART: Start reading when you are ready. (15 points) (page 20, The Fruitcake Special)

2. SECOND PART:

a. One question on Finders Keepers (15 points): What is the name of the game and what is the relationship between the title and the story?

b. One question on Brains (15 points): What was the effect of Gina Capaldi's drug on Max?

3. THIRD AND LAST PART: Listening/repetition exercise (20 points): You will hear 5 clauses with spaces in between. Remember the pauses are provided for you so please do not touch the mouse until the end. Thanks - that will be all. PRESS NEXT TO START (page 62, The Book of Thoughts)

APPENDIX E SCREENSHOTS SHOWING FILING, SAVING AND STORAGE OF ORAL EXAMS 

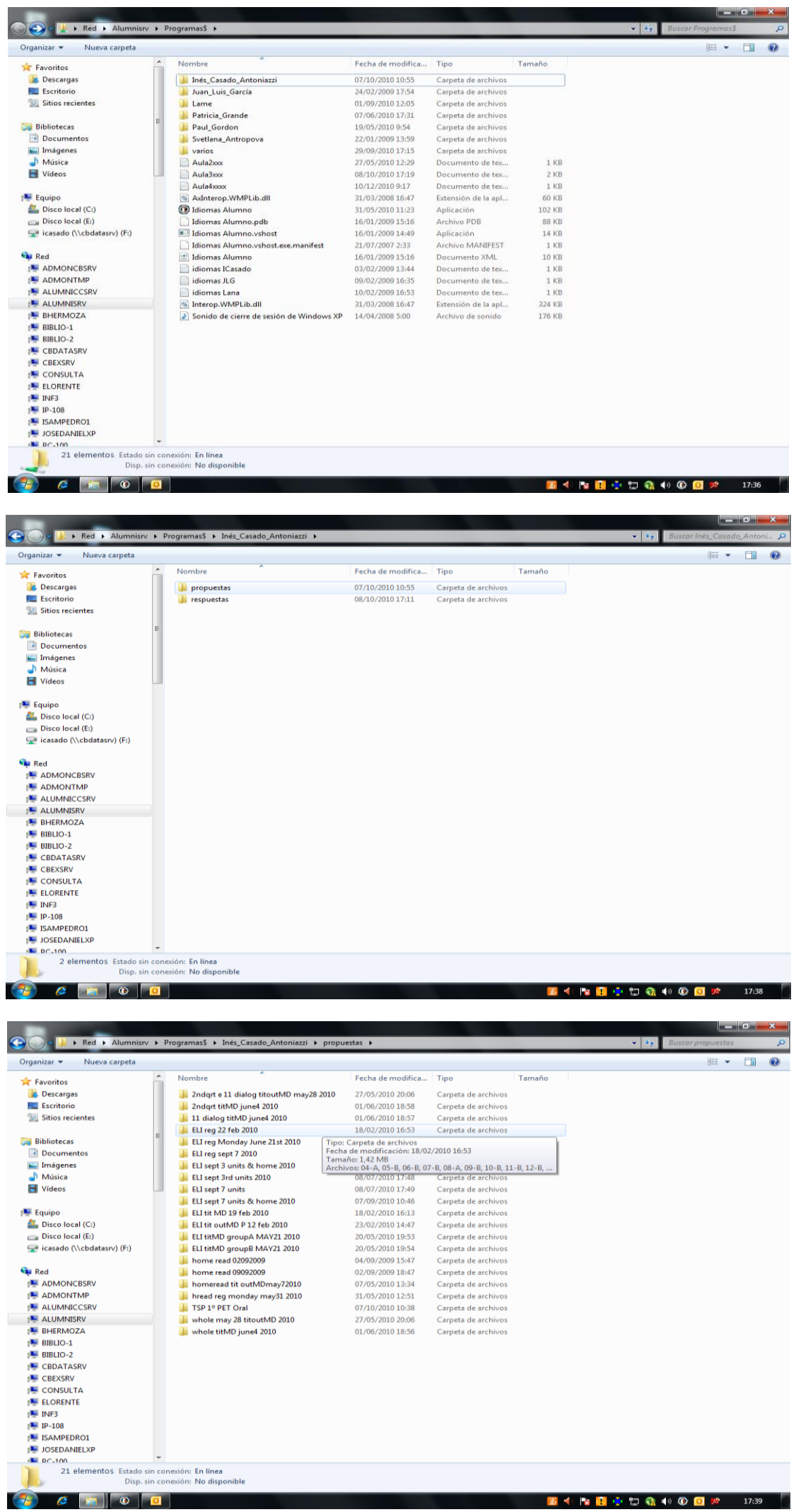


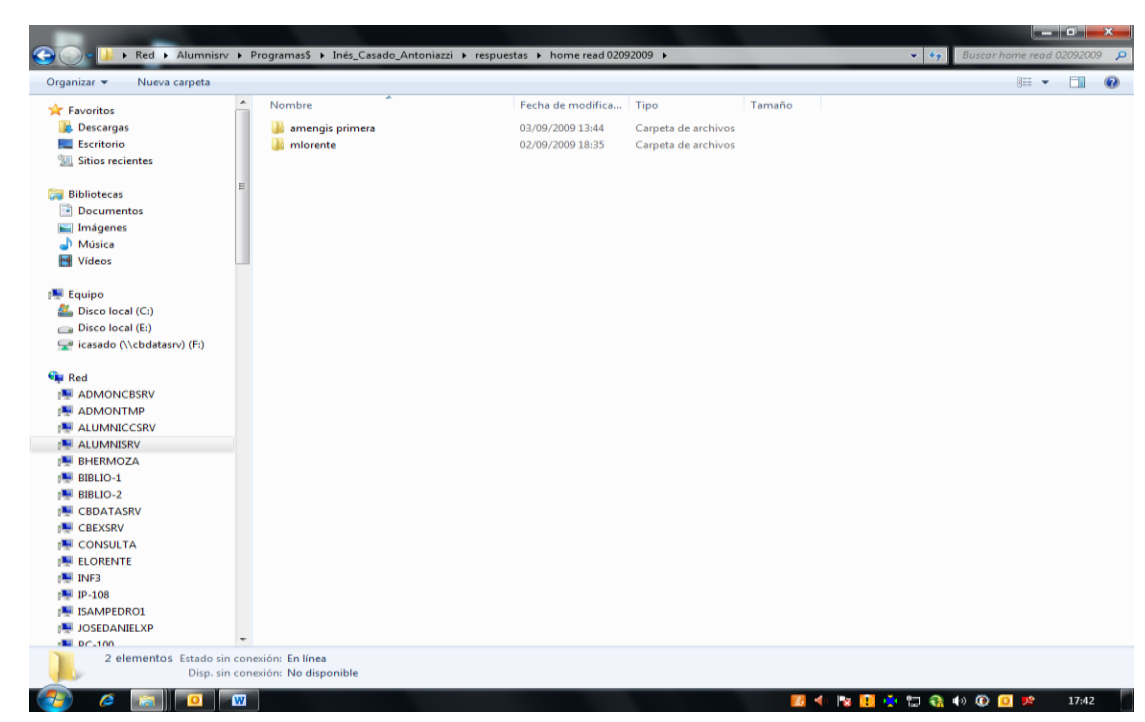

\section{ACKNOWLEDGEMENT}

My appreciation to Carlos Segade and Francesca Colt for their invaluable help in the preparation of this article.

\section{REFERENCES}

[1] AudioAssessment.com. Sloan-C. (17-19/6/2009). Oral exams in online courses. International symposium: Emerging technology applications for online learning. San Francisco, California, USA.

[2] Austin, J. K. (1962). How to do things with words. Oxford: Oxford University Press.

[3] Bachman, L. F. (1990). Fundamental considerations in language testing. Oxford: Oxford University Press.

[4] Brennan, F. (2007). The fruitcake special and other stories. Level 4. Cambridge: Cambridge University Press

[5] Brumfit, C. J. (2001). Individual freedom in language teaching. Oxford: Oxford University Press.

[6] Common European Framework of Reference for Languages: Learning, teaching, assessment. Language examining and test development (October 2002). Prepared under the direction of M. Milanovic (A.L.T.E.), Language Policy Division Strasbourg.

[7] EALTA (Guidelines for Good Practice in Language Testing and Assessment) (20/5/2006). http://www.ealta.eu.org/guidelines.htm (accessed 7/9/2010).

[8] Escamilla, A. (4-5/2/2010). Evaluación de competencias. In $1^{\text {as }}$ Jornadas Internacionales sobre EEEES: Evaluación. Universitat Internacional de Catalunya.

[9] Harmer, J. (2001). The practice of English language teaching ( $3^{\text {rd }}$ edn.). Harlow: Longman. Essex: Pearson Education Limited.

[10] Hymes, D. (1973). On communicative competence. In J. B. Pride \& J. Homes (eds.), Sociolinguistics. Harmondsworth: Penguin Books.

[11] Johnson, K. (1982). Communicative syllabus design and methodology. Oxford: Pergamon.

[12] Johnson, K. \& K. Morrow (1981) (eds.). Communication in the classroom. Harlow, Essex: Longman.

[13] Kenyon \& Malabonga (2001). Comparing examinee attitudes toward computer-assisted and other oral proficiency assessments. Language Learning \& Technology 5.2, 60-83.

[14] Larsen-Freeman, D. (1986). Techniques and principles in language teaching. New York: Oxford University Press.

[15] Larson, J. W. (2000). Testing oral language skills via the computer. Calico Journal 18.1, 54.

[16] Littlewood, W. (1981). Communicative language teaching: An introduction. Cambridge: Cambridge University Press.

[17] López, Alba-Juez, Aragonés \& Molina (2006). e-Oral: A hypermedia web application for English language oral exams within a distance education environment. In Proceedings of the seventh ACIS international conference on software engineering, artificial intelligence, networking, and parallel/distributed computing. The guide to computing literature. Washington: IEEE Computer Society, 343-348.

[18] Madrid, D. \& N. McLaren (eds.) (2004). TEFL in primary education. Granada: Editorial Universidad de Granada.

[19] Munby, J. (1978). Communicative syllabus design. Cambridge: Cambridge University Press.

[20] Pena Díaz, C. \& M. D. Porto Requejo (2010). De la autoevaluación a la evaluación formativa usando las TIC. In M. D. Caballero Rodríguez \& M. J. Pinar Sanz (coords.), Modos y formas de comunicación humana (vol. 2). Cuenca: Servicio de Publicaciones de la Universidad de Castilla-La Mancha, 349-356.

[21] Richards, J. C. \& T. Rogers (1986). Approaches and methods in language teaching. Cambridge: Cambridge University Press.

[22] Sangrà, A. (4-5/2/2010). Las TIC como catalizador de la innovación en la evaluación. In $1^{a s}$ Jornadas Internacionales sobre EEEES: Evaluación. Universitat Internacional de Catalunya.

[23] Widdowson, H. G. (1978). Teaching language as communication. London: Oxford University Press.

[24] Wilkins, D. A. (1972). Linguistics in language teaching. London: Arnold.

[25] Wilkins, D. A. (1976). Notional syllabuses. London: Oxford University Press. 
María I. Casado Antoniazzi completed her $\mathrm{PhD}$ in English with an applied linguistics option at UNED University in Spain in 2006. She is currently a full-time university teacher at the Centro Universitario Villanueva, affiliated with the Universidad Complutense of Madrid. Her research interests include lexicography and ICTs applied to the teaching of languages, including oral assessment software. 